\title{
USE OF HERBAL IMMUNOTROPIC MEDICINES FOR COMPLEX TREATMENT OF GENERALIZED PERIODONTITIS IN PATIENTS WITH CONCOMITANT CORONARY ARTERY DISEASE
}

10.36740/WLek202101102

\author{
Nadiya 0. Stasiuk, Lev Yu. Plaviuk, Sergiy V. Fedorov, Vitaliy I. Gereliuk, Nataliya P. Makhlynets, Nila V. Neyko \\ IVANO-FRANKIVSK NATIONAL MEDICAL UNIVERSITY, IVANO-FRANKIVSK, UKRAINE
}

\begin{abstract}
The aim: Of this study was to improve the efficiency of complex medicamental treatment of generalized periodontitis (GP) in patients with concomitant CAD using of differentiated immunotropic therapy, especially herbal medicine «lmmuno-ton».

Material and methods: 130 patients with GP were observed (43 without and 81 with chronic CAD - stable angina, functional classes II--III (CCS)) with detection of oral hygiene indices for Green-Vermillion, inflammation of gums PMA, bleeding of gums PBI, depth of periodontal pockets (determined by direct method). The levels of TNF- $a$ and sPECAM-1 in gingival fluid were detected by ELISA method.

Results: The following article is dedicated to studying on the effectiveness of the proposed method of GP I and II degree of development treatment in patients with a concomitant coronary artery disease (CAD) using of herbal medicines with immunomodulating effect. The offered methods provide disappearance of clinical signs of inflammation in the periodontal tissues and prevention of inflammation recurrence in the long terms. Also, it was proved that usage of the forward method of the GP immunotropic therapy with including of herbal immunomodulators leads to normalization of dynamics of tumor necrosis factor -alfa (TNF-a) and soluble platelet-endothelial cell adhesion molecule - 1 (sPECAM-1) in oral fluid of abovementioned contingent of patients.

Conclusions: The progression of generalized periodontitis in patients with stable coronary heart disease is accompanied with manifestation of systemic inflammation, which have been reduced by immunomodulator Immuno-Ton and extratemporal gel with "Enterosgel" and herbal concentrate "Dzherelo".
\end{abstract}

KEY WORDS: generalized periodontitis, coronary artery disease, immunotropic therapy, cytokines

Wiad Lek. 2021;74(1):11-16

\section{INTRODUCTION}

Coronary artery disease (CAD) is a major cause of death and disability in developed countries. Although CAD mortality rates worldwide have declined over the past four decades, CAD remains responsible for about one-third or more of all deaths in individuals over age $35[1,2,3,4]$.

Periodontitis is a disease of the supporting tissues of the teeth, which are naturally inflammatory [5]. Not only does it affect general health, it also forms a component of the global burden of chronic diseases. Geographical variations are found in the prevalence of periodontal disease and they are mainly attributed to variations in socioeconomic conditions, behavioural factors, systemic conditions of people and oral hygiene patterns [5]. The National Health and Nutrition Examination Survey III (NHANES III) between 1988 and 1994 demonstrated that gingival inflammation occurs in 50\% of the adult population [7]. The economic burden of this disease can be estimated from various reports. One such report indicates that periodontal and preventive procedures totalled 14.3 billion dollars, of which, 4.4 billion dollars was spent on periodontal services to directly treat the disease [8].

Issues of the probable link between periodontal disease and CAD have been under active debate for at least the last
20 years. Both ailments are multifactorial inflammatory conditions with many common risk factors (smoking, type 2 diabetes, obesity, etc.), and the key to their progression and development is the comprehensive impact of inflammation [9]. Examination of patients with stable CAD and its unstable variant - acute coronary syndrome, using coronary angiography showed a close relationship with high average indices of periodontal lesions (gingival recession, bleeding after probing, pockets depth etc.), which allowed the authors to connect of both ailments [9].

The explanations for the development and exacerbation of atherosclerotic plaques in periodontitis patients include: (1) bacteremia, (2) a pro-inflammatory state, (3) a prothrombotic state, (4) an overactive immunity, (5) dyslipidemia, and (6) common genetic risk factors. Most likely, these plausible mechanisms play all simultaneously a role [9]. Some immunological factors are involved in the development and control periodontitis, such as: the participation of inflammatory cells in local inflammation, the synthesis of chemotaxis proteins with activation of the complement system and a range of antimicrobial peptides, such as defensins, cathelicidin and saposins. The integration of pathogen-associated molecular patterns (PAMPs) from microorganisms with their surface receptors in the 
immune cells, induces the production of several cytokines and chemokines that presents either a pro- and/or anti-inflammatory role by stimulating the secretion of a great variety of antibody subtypes and the activation of mechanisms of controlling the disease, such as the regulatory $\mathrm{T}$ cells $[6,10]$.

Traditional treatment of GP is to eliminate inflammation in the periodontium by removing local irritating factors and use in local and general therapy antimicrobial, anti-inflammatory, antioxidant, osteotropic, antihistamine, vitamin preparations [11]. However, these schemes of treatment rarely supplemented agents that specifically and purposefully influence the immune condition especially in patients with concomitant CAD.

At present, there is widespread interest in the relationship between CAD and periodontitis at the genetic level. One of the first and well-replicated gene loci in coronary heart disease is ANRIL [1]. It is regulatory and does not contain a protein-coding gene. Importantly, it is a pleiotropic gene region that is also responsible for the development of type 2 diabetes, ischemic stroke and Alzheimer's disease [9]. Subsequently established the importance of ANRIL in the development of periodontitis.

Thus, a significant number of interventional, epidemiological and functional studies indicate a possible link between generalized periodontitis and coronary heart disease. Oral bacteria and their products may be involved in all stages of atherogenesis alone or indirectly. Generalized periodontitis, in our opinion, should be regarded as a systemic process that requires not only local but also general treatment.

The following article is dedicated to studying on the effectiveness of the proposed method of GP I and II degree of development treatment in patients with a concomitant CAD using of herbal medicines with immunomodulating effect. The offered methods provide disappearance of clinical signs of inflammation in the periodontal tissues and prevention of inflammation recurrence in the long terms. Also, it was proved that usage of the forward method of the GP immunotropic therapy with including of herbal immunomodulators leads to normalization of dynamics of tumor necrosis factor -alfa (TNF- $\alpha$ ) and soluble platelet-endothelial cell adhesion molecule -1 (sPECAM-1) in oral fluid of abovementioned contingent of patients.

\section{THE AIM}

To improve the efficiency of complex medicamental treatment of GP in patients with concomitant CAD using of differentiated immunotropic therapy, especially herbal medicine «Immuno-ton».

\section{MATERIALS AND METHODS}

130 patients with GP were observed (43 without and 81 with chronic CAD - stable angina, functional classes IIIII (CCS)). The diagnosis of periodontitis was verified in accordance of last recommendation [10]. Stable angina was verified due European Cardiology Society (2013) guidelines. All patients signed of Informed consent; design of this trial was approved by local ethic committee.

The exclusion criteria were the presence in patients of cantilever orthopedic structures, dental implants, plate removable dentures, complex dental and jaw abnormalities and deformities; acute coronary syndrome (up to 12 months); stroke, transient ischemic attack (TIA) for up to three months; unstable cardiovascular conditions; implanted intracardiac devices; symptomatic hypertension; alcohol or drug addiction; tumors; known inflammatory diseases of infectious or non-infectious nature; chronic kidney disease (CKD) stage IV-V; liver failure; anemia and other blood diseases; decompensated diabetes mellitus (diabetes); pregnancy and breastfeeding; incapacity and limited capacity; known warnings or contraindications to the use of investigational drugs; refusal to sign an informed consent to participate in the study.

We used the preparation "Immuno-tone" (registration no UA/2179/01/01 from 03.11.2009) and phytoconcentrate "Dzherelo" (registration no. 02568182/031880/01 dated 05.02.2009). Immuno-tone contains eleutherococcus extract, tincture of rhizomes with purple echinacea roots, tincture of hypericum; this drug has a combined adaptogenic and immunomodulatory action due to biologically active substances of medicinal plants. "Immuno-tone" increases the body's natural forces against the influence of adverse environmental factors, stimulates the immune system, gently tones the central nervous system. The immunomodulatory effect is due to the stimulation of mainly cellular immunity, an increase in the number of T-lymphocytes, an increase in the phagocytic activity of leukocytes, the release of some cytokines and is used in chronic recurrent inflammatory diseases. Phytoconcentrate "Dzherelo" was created on the basis of composition of food and medicinal plants. The components of the drug activate the processes of energy formation in cells, stimulate redox reactions, promote the regeneration of cellular organelles, as well as stimulate local nonspecific immunity of the oral cavity.

The therapeutic efficacy of the drugs was determined by their influence on the subjective and objective clinical features of the GP course (oral hygiene indices for Green-Vermillion, inflammation of gums PMA, bleeding of gums PBI, depth of periodontal pockets (determined by direct method).

The levels of TNF- $\alpha$ and sPECAM-1 in gingival fluid were detected by ELISA method with use of TNF- $\alpha$ ELISA kit (Vector-Best, Russia) and sPECAM-1 ELISA BMS229 kit (Bender MedSystems, Austria). Statistical analysis was performed with Statistica system software, version 12.0. Categorical variables are presented as percentages, whereas continuous variables are presented as mean $(\mathrm{M})$ and standart error of mean $(\mathrm{m})$ if normally distributed, or as median and interquartile range (Me [IQR]), if not. Categorical variables were compared by the $\chi 2$ test and continuous variables by the $t$ test or the Mann-Whitney $U$ test. A $p$ value of $<0.05$ was considered statistically significant. All tests were 2 -sided. 
All observed patients were divided into following groups due to stage of GP development, presence of concomitant CAD and algorithm of proposed treatment: 1A (10 persons) - patients with generalized periodontitis I stage which received standard treatment; 1C (22 persons) patients with generalized periodontitis I stage and stable angina FC II-III which received standard treatment of both diseases and additional instillation to periodontal pockets of extratemporal gel with "Enterosgel" and herbal concentrate "Dzerelo"; 2A (10 persons) - patients with generalized periodontitis II stage which received standard treatment; 2C (22 persons) - patients with generalized periodontitis II stage and stable angina FC II-III which received standard treatment of both diseases and additional instillation to periodontal pockets of extratemporal gel with "Enterosgel" and herbal concentrate "Dzerelo"; $1 \mathrm{~B}(10$ persons) - patients with generalized periodontitis I stage which received standard treatment and immunomodulator "Imuno-ton" (GalychPharm, Ukraine) $15 \mathrm{ml}$, twice a day, in the morning, after meals; $1 \mathrm{D}$ (23 persons) - patients with generalized periodontitis I stage and stable angina FC II-III which received standard treatment of both diseases and additional instillation to periodontal pockets of extratemporal gel with "Enterosgel" and herbal concentrate "Dzherelo", and immunomodulator "Imuno-ton" $15 \mathrm{ml}$, twice a day, in the morning, after meals; $2 \mathrm{~B}$ (10 persons) - patients with generalized periodontitis II stage which received standard treatment and immunomodulator "Imuno-ton" $15 \mathrm{ml}$, twice a day, in the morning, after meals; $2 \mathrm{D}$ (23 persons) - patients with generalized periodontitis II stage and stable angina FC II-III which received standard treatment of both diseases and additional instillation to periodontal pockets of extratemporal gel with "Enterosgel" and herbal concentrate "Dzerelo", and immunomodulator "Imuno-ton" $15 \mathrm{ml}$, twice a day, in the morning, after meals.

Evaluation of treatment efficacy was performed immediately after the proposed treatment and at 3,6 and 12 months of follow-up.

\section{RESULTS}

Patients with GP I and II stages of development and concomitant CAD after 2 - 3 sessions had an improvement in the condition of periodontal tissue in relation to patients' complaints: halitosis, decreased feeling of discomfort or gum pain, normalization of gum color, disappeared or changed of gums bleeding, changing nature or disappearing exudate. Objective examination showed a dynamic decrease in the symptoms of symptomatic gingivitis, in most patients before 3 sessions completely stopped exudation from the periodontal pockets The mucous membrane of the gums became dense, became pale pink in color, decreased recession, swelling and bleeding on palpation. The timely conducted of curettage (with the second stage of GP development) in the complex treatment led to a decrease in the depth of the periodontal pockets, termination of exudation and epithelialization of the bottom. Normalization of clinical parameters in all groups of patients, regardless of the proposed treatment, occurred at 3-4 visits. The number of treatment sessions depended on the degree of GP development and the severity of symptomatic gingivitis. The average number of sessions in subgroups of patients with GP I and II stages of development using the proposed method of treatment was $3.25 \pm 0.42$; in subgroups of patients with GP I and II stages of development using traditional treatment $-3.75 \pm 0.47$. At the end of treatment, objective examination showed normalization of the color, texture and configuration of the gums.

It should be emphasized that the results obtained demonstrate a qualitative and equal randomization of patients by groups.

One of the main criteria for the severity of the inflammatory process in the periodontium is the manifestation of symptomatic gingivitis, which can be evaluated by the dynamics of the PMA inflammation index and bleeding PBI.

During the main $(1 \mathrm{~B}, 1 \mathrm{D})$ and comparison subgroups (1A, $1 \mathrm{C})$, positive PMA dynamics were observed during treatment, the area of tissues covered by inflammation decreased from $(31.48 \pm 0.75) \%$ and $(34.64 \pm 0.86) \%$ to $(4.6 \pm 0.4) \%$ and $(4.5 \pm 0.4) \%$ - in subgroups $1 \mathrm{~B}$ and $1 \mathrm{D}$ respectively; from $(32.65 \pm 0.77) \%$ and $(34.15 \pm 0.85) \%$ to $(5.3 \pm 0.5) \%$ and $(5.1 \pm 0.5) \%$ in the $1 \mathrm{~A}$ and $1 \mathrm{C}$ respectively. However, in subgroups $1 \mathrm{~B}$ and $1 \mathrm{D}$, this process proceeded more efficiently, remaining at 9.84; 11.24; 5.52 times and $9.62 ; 10.83 ; 6.66$ times lower than the baseline by 3,6 and 12 months respectively, whereas in the comparison subgroups $1 \mathrm{~A}$ and $1 \mathrm{C}$, this indicator decreased in the corresponding time in $5.27 ; 4.8 ; 1.94$ times and $5.5 ; 5.17 ; 2.07$ times with statistically significant difference between subgroups at 3 , 6 and 12 months $(\mathrm{p}<0.001)$. Immediately after treatment, there was a 3-times decrease in the PBI index in the main subgroups and 2.5-times in the comparison subgroups, which proves the clinical effectiveness of the treatment in each subgroup. Significant difference of indicators was found with respect to the index of bleeding of PBI for 3 months in the main subgroups $1 \mathrm{~B}$ and $1 \mathrm{D}-$ a decrease in 3.8 times $(\mathrm{p}<0.001)$ compared to the initial values; in comparison subgroups $1 \mathrm{~A}$ and $1 \mathrm{C}$, this indicator decreased in 2.4 and 2.59 times respectively $(\mathrm{p}<0.05)$. At 3,6 and 12 months, a clear significant difference in the magnitude of the PBI bleeding index was established between groups $(\mathrm{p}<0.001)$.

Indicators of bleeding indices and PMA are directly correlated with indicators of oral hygiene and its changes in the course of treatment and preventive measures.

At the stage immediately after the treatment, a positive dynamics was observed in terms of periodontal pockets depth, also. Periodontal pockets decreased within $0.76 \mathrm{~mm}$ and $1.12 \mathrm{~mm}$ in the major subgroups, $0.21 \mathrm{~mm}$ and 0.64 $\mathrm{mm}$ in the comparison subgroups. This indicator remained stable in dynamics in the main subgroups during other periods, so for 3, 6 and 12 months the periodontal pockets depth in subgroup $1 \mathrm{~B}$ decreased to $0.78 \mathrm{~mm}, 0.66 \mathrm{~mm}$ and $0.64 \mathrm{~mm}$ respectively; in subgroup $1 \mathrm{D}$ - decreased to $1.19 \mathrm{~mm}, 0.93 \mathrm{~mm}$, and $0.9 \mathrm{~mm}$ respectively, significantly different from similar values in the comparison subgroups $(p<0.001)$, indicating remission of the dystrophic-inflam- 
matory process in the periodontium.

In the study of index indicators between the main and the comparison group, the dynamics of changes that characterize the activity of the pathological process in periodontal tissues in patients with GP II stage of development and with concomitant coronary heart disease at the stages of treatment were detected, compared with the initial data and between groups. As a result of the clinical examination and index evaluation, it was found that in the main and in the comparison group, directly after the complex treatment in comparison with the initial data, there is a significant decrease in a number of indicators (periodontal pockets depth, PBI index, PMA, hygienic condition, tooth mobility). In general, analyzing the data obtained, it can be stated that the treatment regimens for patients with GP in both groups are adequately selected, as evidenced by some clinical effect.

Positive dynamics of PMA index was observed in the main and in the comparison group: in subgroups $2 \mathrm{~B}$ and $2 \mathrm{D}$ respectively $(45.8 \pm 0.93) \%$ and $(44.4 \pm 0.91) \%$ to $(5.48 \pm 0.4) \%$ and $(5.6 \pm 0.4) \%$; in subgroups $2 \mathrm{~A}$ and $2 \mathrm{C}$ to $(45.5 \pm 0.93) \%$ and $(45 \pm 0.93) \%$ to $(6.51 \pm 0.53) \%$ and $(6.75 \pm 0.5) \%$. However, in the main subgroups this process was more efficient and maintained positive dynamics, remaining below baseline in subgroup $2 \mathrm{~B}$ for 3 months - 9.35 times, 5.39 and 3.39 times for 6 and 12 months respectively; in the $2 \mathrm{D}$ subgroup 3 months -8.88 times, 4.53 and 3.22 times 6 and 12 months respectively. Whereas in the comparison group this indicator decreased in the corresponding terms - in the subgroup $2 \mathrm{~A}$ for 3 months -6.23 times, 4.0 and 2.37 times for 6 and 12 months respectively; in the $2 \mathrm{C}$ subgroup at 3 months -6.34 times, 3.3 and 2.4 times at 6 and 12 months respectively $(\mathrm{p}<0.001)$.

There was a decrease in the bleeding index of PBI (in the main group - 4.8, in the comparison group - 3 times), which proves the clinical effectiveness of the conducted treatment in each group, as well. A clear difference in the PBI indexes was found at 3 months - a decrease in 10.38 times in subgroup $2 \mathrm{~B}$ and 8.84 times in subgroup $2 \mathrm{D}(\mathrm{p}$ $<0.001$ ), whereas in subgroups $2 \mathrm{~A}$ and $2 \mathrm{C}$ this indicator decreased in 3.93 and 3.86 times respectively $(\mathrm{p}<0.001)$. At 3 months there was a significant difference in the value of bleeding index between subgroups ( $\mathrm{p}<0.05)$, at 6 and 12 months $(\mathrm{p}<0.001)$.

6 months after the treatment was observed stabilization of periodontal tissues condition in all subgroups, with exception of isolated cases.

The level of TNF- $\alpha$ in gingival fluid of patients with stable angina was higher for $22.13 \%$ and for $32.29 \%$ in observed patients with generalized periodontitis I and II stage relatively $(p<0.05)$. Its concentration was significant decreased after treatment in all groups, but more strong in patients with additional use of immunomodulators (see table 1). In patients with angina pectoris normalization of TNF-a levels was more slowly compared group without coronary atherosclerosis.

Similar results were obtained accordance of levels of sPECAM-1 in gingival fluids of observed patients (see table 2).

\section{DISCUSSION}

Using of immunomodulating medicines of herbal origin contributes of local and systemic immunity normalization, inhibition of interdental and interradicular septas inflammatory resorption and stimulation of periodontal tissues reconstruction speed $[6,7]$.

It is reasonable to prefer medicines with many-sided activity, that afford to have an effect on different aspects of aetiology and pathogenesis of disease for optimization of complex therapy efficiency, taking into account polyaetiology of GP [5].

The resulted data confirming that GP with concomitant CAD develops on a ground of local and systemic immunity disturbances. Prominent changes of proinflammatory cytokines in oral liquid of examined contingent of patients may be explained by both side influence (GP - CAD) on compensatory mechanisms, which regulate homeostasis of immune system. [9].

It's known, TNF- $\alpha$ is a pleiotropic pro-inflammatory cytokine released by a variety of different cell types in response to various stimuli, including bacteria, parasites, viruses, cytokines and mitogens. It is involved in systemic and local inflammation via different signal pathways, inducing a broad range of genes. TNF- $\alpha$ regulates a host response to infection and its deregulation is implicated in the pathogenesis of numerous complex diseases, including periodontitis. This cytokine was shown to drive several biological processes such as induction of inflammatory mediators, for instance, matrix metalloproteases, chemokines and prostaglandins, endothelial cell activation and endothelial-leukocyte interactions, monocyte adhesion, mediating bone remodelling, and oxidative processes $[12,13]$. TNF- $\alpha$ induce bone resorption and up-regulate prostaglandin E2 (PGE2) and collagenases secretion and is produced by many cell types including macrophages, neutrophils, keratinocytes, fibroblasts, NK cells, $\mathrm{T}$ and $\mathrm{B}$ cells in the periodontium. Thise cytokine induces the up-regulation of adhesion molecules on leucocytes and endothelial cells, stimulating the production of chemokines that recruit circulating leucocytes to sites of inflammation, and inducing expression of other inflammatory mediators that potentiate inflammatory responses [13]. PECAM-1/CD31 is a $130-\mathrm{kD}$ vascular cell adhesion and signaling molecule of the immunoglobulin (Ig) superfamily that is expressed on the surface of circulating platelets, monocytes, neutrophils, and selected T-cell subsets. It is also a major constituent of the endothelial cell intercellular junction and plays a role in neutrophil recruitment at inflammatory sites. There is good evidence to suggest that PECAM-1 is a key participant in the adhesion cascade leading to extravasation of leukocytes during the inflammatory process [14]. Many studies suggest that chronic periodontitis is an independent risk factor for systemic vascular disease and may result in stimulation of the synthesis of acute phase protein by cytokines released by periodontal high endothelial cells [15]. However, tissue expression of adhesion molecules has not been substantially evaluated in the gingiva of patients with chronic periodontitis. This is significant in relation to potential therapy targeting expression of the adhesion molecules [14]. 
Table I. Dynamics of gingival fluid levels of TNF- $a(\mathrm{pg} / \mathrm{ml})$ in patients with generalized periodontitis

\begin{tabular}{|c|c|c|c|c|c|c|c|c|}
\hline \multirow{2}{*}{ Period } & \multicolumn{8}{|c|}{ Groups of observed patients } \\
\hline & $1 A, n=10$ & $1 C, n=22$ & $2 A, n=10$ & $2 C, n=22$ & $1 B, n=10$ & $1 D, n=23$ & $2 B, n=10$ & $2 D, n=23$ \\
\hline $\begin{array}{c}\text { Before } \\
\text { treatment }\end{array}$ & $41.56 \pm 2.45$ & $54.63 \pm 3.41$ & $51.24 \pm 2.97$ & $67.44 \pm 2.31$ & $44.33 \pm 2.67$ & $55.67 \pm 3.47$ & $52.47 \pm 2.95$ & $69.76 \pm 2.54$ \\
\hline 1 month & $\begin{array}{c}32.99 \pm 3.52 \\
P<0.01\end{array}$ & $\begin{array}{c}41.14 \pm 2.91 \\
P<0.01\end{array}$ & $\begin{array}{c}43.14 \pm 3.23 \\
P<0.01\end{array}$ & $\begin{array}{c}53.67 \pm 2.77 \\
P<0.01\end{array}$ & $\begin{array}{c}27.35 \pm 2.21 \\
P<0.01\end{array}$ & $\begin{array}{c}37.57 \pm 2.89 \\
P<0.01\end{array}$ & $\begin{array}{c}39.77 \pm 3.12 \\
P<0.01\end{array}$ & $\begin{array}{c}51.47 \pm 3.32 \\
P<0.01\end{array}$ \\
\hline 3 month & $\begin{array}{c}31.47 \pm 2.78 \\
P<0.01 \\
P^{1}>0.05\end{array}$ & $\begin{array}{c}39.97 \pm 3.11 \\
P<0.01 \\
P^{1}>0.05\end{array}$ & $\begin{array}{c}41.11 \pm 2.54 \\
P<0.01 \\
P^{1}>0.05\end{array}$ & $\begin{array}{c}51.23 \pm 3.14 \\
P<0.01 \\
P^{1}>0.05 \\
\end{array}$ & $\begin{array}{c}25.67 \pm 2.78 \\
P<0.01 \\
P^{1}>0.05\end{array}$ & $\begin{array}{c}36.77 \pm 2.91 \\
P<0.01 \\
P^{1}>0.05 \\
\end{array}$ & $\begin{array}{c}35.67 \pm 3.11 \\
P<0.01 \\
P^{1}>0.05\end{array}$ & $\begin{array}{c}46.77 \pm 3.98 \\
P<0.01 \\
P^{1}>0.05 \\
\end{array}$ \\
\hline 6 month & $\begin{array}{c}29.46 \pm 3.71 \\
P<0.01 \\
P^{1}>0.05 \\
P^{2}>0.05\end{array}$ & $\begin{array}{c}36.82 \pm 3.23 \\
\mathrm{P}<0.01 \\
\mathrm{P}^{1}>0.05 \\
\mathrm{P}^{2}>0.05\end{array}$ & $\begin{array}{c}37.79 \pm 3.45 \\
P<0.01 \\
P^{1}>0.05 \\
P^{2}>0.05\end{array}$ & $\begin{array}{c}49.67 \pm 2.23 \\
\quad P<0.01 \\
P^{1}>0.05 \\
P^{2}>0.05\end{array}$ & $\begin{array}{c}26.14 \pm 3.22 \\
P<0.01 \\
P^{1}>0.05 \\
P^{2}>0.05\end{array}$ & $\begin{array}{c}31.54 \pm 3.43 \\
\mathrm{P}<0.01 \\
\mathrm{P}^{1}<0.05 \\
\mathrm{P}^{2}<0.05\end{array}$ & $\begin{array}{c}32.13 \pm 3.34 \\
\mathrm{P}<0.01 \\
\mathrm{P}^{1}<0.05 \\
\mathrm{P}^{2}>0.05\end{array}$ & $\begin{array}{c}47.14 \pm 3.37 \\
P<0.01 \\
P^{1}>0.05 \\
P^{2}>0.05\end{array}$ \\
\hline 12 month & $\begin{array}{c}30.47 \pm 2.87 \\
P<0.01 \\
P^{1}>0.05 \\
P^{2}>0.05 \\
P^{3}>0.05\end{array}$ & $\begin{array}{c}38.91 \pm 2.11 \\
\mathrm{P}<0.01 \\
\mathrm{P}^{1}>0.05 \\
\mathrm{P}^{2}>0.05 \\
\mathrm{P}^{3}>0.05\end{array}$ & $\begin{array}{c}38.11 \pm 3.31 \\
P<0.01 \\
P^{1}>0.05 \\
P^{2}>0.05 \\
P^{3}>0.05\end{array}$ & $\begin{array}{c}48.45 \pm 3.11 \\
P<0.01 \\
P^{1}>0.05 \\
P^{2}>0.05 \\
P^{3}>0.05\end{array}$ & $\begin{array}{c}26.74 \pm 2.31 \\
P<0.01 \\
P^{1}>0.05 \\
P^{2}>0.05 \\
P^{3}>0.05\end{array}$ & $\begin{array}{c}30.89 \pm 2.78 \\
\mathrm{P}<0.01 \\
\mathrm{P}^{1}<0.05 \\
\mathrm{P}^{2}<0.05 \\
\mathrm{P}^{3}>0.05\end{array}$ & $\begin{array}{c}32.76 \pm 2.98 \\
P<0.01 \\
\mathrm{P}^{1}<0.05 \\
\mathrm{P}^{2}>0.05 \\
\mathrm{P}^{3}>0.05\end{array}$ & $\begin{array}{c}43.56 \pm 2.99 \\
\mathrm{P}<0.01 \\
\mathrm{P}^{1}<0.05 \\
\mathrm{P}^{2}<0.05 \\
\mathrm{P}^{3}<0.05\end{array}$ \\
\hline
\end{tabular}

Notes: $p$ - significance in compared groups during follow-up period

Table II. Dynamics of gingival fluid levels of sPECAM-1 ( $\mathrm{ng} / \mathrm{ml})$ in patients with generalized periodontitis

\begin{tabular}{|c|c|c|c|c|c|c|c|c|}
\hline \multirow{2}{*}{ Period } & \multicolumn{8}{|c|}{ Groups of observed patients } \\
\hline & $1 A, n=10$ & $1 C, n=22$ & $2 A, n=10$ & $2 C, n=22$ & $1 B, n=10$ & $1 D, n=23$ & $2 B, n=10$ & $2 D, n=23$ \\
\hline \multirow{3}{*}{$\begin{array}{l}\text { Before } \\
\text { treatment }\end{array}$} & 104.45 & 128.77 & 107.87 & 147.45 & 107.11 & 135.78 & 114.45 & 146.21 \\
\hline & {$[91.34 ;$} & {$[111.43 ;$} & {$[93.45$} & {$[121.23 ;$} & {$[94.75 ;$} & {$[121.47 ;$} & {$[91.42 ;$} & {$[120.12 ;$} \\
\hline & 119.54] & 136.74] & 121.42] & 167.42] & 129.25] & 147.98] & 135.87] & 165.32] \\
\hline \multirow{4}{*}{1 month } & 75.78 & 97.56 & 91.21 & 107.67 & 61.45 & 91.78 & 90.42 & 91.45 \\
\hline & {$[55.34 ;$} & {$[87.45$} & {$[75.45$} & {$[89.78$} & {$[48.78 ;$} & {$[79.54 ;$} & {$[74.74$} & {$[78.79$} \\
\hline & 99.67] & 117.32] & 108.23] & 114.11] & 87.98] & 103.22] & 106.23] & 102.12] \\
\hline & $\mathrm{P}<0.01$ & $\mathrm{P}<0.01$ & $\mathrm{P}<0.01$ & $\mathrm{P}<0.01$ & $\mathrm{P}<0.01$ & $P<0.01$ & $P<0.01$ & $P<0.01$ \\
\hline \multirow{5}{*}{3 month } & 74.23 & 93.52 & 89.78 & 106.35 & 54.45 & 81.78 & 79.79 & 76.51 \\
\hline & {$[56.34 ;$} & {$[83.41 ;$} & {$[76.45$} & [91.25; & {$[38.44 ;$} & {$[65.47 ;$} & {$[64.51 ;$} & [54.89; \\
\hline & $96.45]$ & 112.34] & 107.54] & $112.74]$ & 74.11] & $92.23]$ & 91.88] & 98.14] \\
\hline & $P<0.01$ & $P<0.01$ & $P<0.01$ & $P<0.01$ & $P<0.01$ & $P<0.01$ & $P<0.01$ & $P<0.01$ \\
\hline & $P^{1}>0.05$ & $\mathrm{P}^{1}>0.05$ & $P^{1}>0.05$ & $P^{1}>0.05$ & $\mathrm{P}^{1}<0.05$ & $\mathrm{P}^{1}<0.05$ & $\mathrm{P}^{1}<0.05$ & $\mathrm{P}^{1}<0.05$ \\
\hline \multirow{6}{*}{6 month } & 71.23 & 92.44 & 87.34 & 104.12 & 53.74 & 79.89 & 78.14 & 75.16 \\
\hline & {$[55.76 ;$} & {$[85.42 ;$} & {$[72.45$} & {$[92.12 ;$} & [39.78; & {$[66.45 ;$} & {$[63.61 ;$} & {$[56.14 ;$} \\
\hline & 98.34] & 109.85] & $105.15]$ & 11.85] & 73.45] & 91.74] & $90.45]$ & 98.27] \\
\hline & $P<0.01$ & $P<0.01$ & $P<0.01$ & $P<0.01$ & $P<0.01$ & $P<0.01$ & $P<0.01$ & $P<0.01$ \\
\hline & $P^{1}>0.05$ & $\mathrm{P}^{1}>0.05$ & $P^{1}>0.05$ & $\mathrm{P}^{1}>0.05$ & $\mathrm{P}^{1}<0.05$ & $\mathrm{P}^{1}<0.05$ & $\mathrm{P}^{1}<0.05$ & $\mathrm{P}^{1}<0.05$ \\
\hline & $P^{2}>0.05$ & $P^{2}>0.05$ & $P^{2}>0.05$ & $P^{2}>0.05$ & $P^{2}>0.05$ & $\mathrm{P}^{2}>0.05$ & $\mathrm{P}^{2}>0.05$ & $P^{2}>0.05$ \\
\hline \multirow{7}{*}{12 month } & 69.34 & 83.78 & 88.78 & 105.57 & 54.87 & 80.42 & 80.11 & 74.58 \\
\hline & [49.34; & {$[63.45$} & [73.87; & {$[93.45 ;$} & [38.78; & {$[67.45 ;$} & {$[66.63 ;$} & [53.71; \\
\hline & 80.34] & 105.15] & $104.75]$ & 113.75] & 73.45] & 94.77] & 93.14] & 95.98] \\
\hline & $P<0.01$ & $P<0.01$ & $P<0.01$ & $P<0.01$ & $P<0.01$ & $P<0.01$ & $P<0.01$ & $P<0.01$ \\
\hline & $\mathrm{P}^{1}>0.05$ & $\mathrm{P}^{1}<0.05$ & $\mathrm{P}^{1}>0.05$ & $\mathrm{P}^{1}>0.05$ & $\mathrm{P}^{1}<0.05$ & $\mathrm{P}^{1}<0.05$ & $\mathrm{P}^{1}<0.05$ & $\mathrm{P}^{1}<0.05$ \\
\hline & $P^{2}>0.05$ & $\mathrm{P}^{2}<0.05$ & $P^{2}>0.05$ & $P^{2}>0.05$ & $P^{2}>0.05$ & $P^{2}>0.05$ & $P^{2}>0.05$ & $P^{2}>0.05$ \\
\hline & $P^{3}>0.05$ & $\mathrm{P}^{3}<0.05$ & $P^{3}>0.05$ & $P^{3}>0.05$ & $P^{3}>0.05$ & $\mathrm{P}^{3}>0.05$ & $\mathrm{P}^{3}>0.05$ & $P^{3}>0.05$ \\
\hline
\end{tabular}

Notes: $p$ - significance in compared groups during follow-up period

\section{CONCLUSIONS}

1. The progression of generalized periodontitis in patients with stable coronary heart disease is accompanied with manifestation of systemic inflammation, which is evidenced by the increase in oral fluid levels of TNF-a (in 2.28 and 2.86 times for I and II stages) and sPECAM-1 (in 2.66 and 2.99 times respectively). Strong positive relationship between TNF- $\alpha$ and sPECAM-1 content in oral liquid and PMA inflammation indices was detected.

2. The use of herbal immunotropic drugs in the complex treatment of generalized periodontitis in patients with stable coronary heart disease reduces its clinical manifes- 
tations (PMA - on 79.4\%, PBI - on $63.2 \%$, depth of periodontal pockets - on 27.4\%), improves the immunogram, reduces the manifestations of systemic inflammation (the level of TNF- $\alpha$ in the oral liquid decreased by an average on 27.3\%). It was found that in the long term (after 6 and 12 months) after treatment, the stabilization of periodontal tissues conditions persists and there is a decrease in the number of relapses, by an average on $24.2 \%$.

3. Additional prescription of immunomodulator Immuno-Ton and extratemporal gel with "Enterosgel" and herbal concentrate "Dzherelo" caused more significant normalizing of local inflammation activity in patients with generalized periodontitis and concomitant CAD.

\section{REFERENCES}

1. RosamondW.,Flegal K., FurieK. et al. Heart disease and stroke statistics-2008 update: a report from the American Heart Association Statistics Committee and Stroke Statistics Subcommittee. Circulation. 2008;117(4):e25.

2. Benjamin E.J., Blaha M.J., Chiuve S.E. et al. Heart Disease and Stroke Statistics-2017 Update: A Report From the American Heart Association. Circulation. 2017;135(10):e146.

3. Lloyd-Jones D.M., Larson M.G., Beiser A., Levy D. Lifetime risk of developing coronary heart disease. Lancet. 1999;353(9147):89.

4. Mozaffarian D., Benjamin E.J., Go A.S. et al. Executive Summary: Heart Disease and Stroke Statistics--2016 Update: A Report From the American Heart Association. Circulation. 2016;133(4):447-54.

5. Al Qahtani N.A., Joseph B., Deepthi A., Vijayakumari B.K. Prevalence of chronic periodontitis and its risk determinants among female patients in the Aseer Region of KSA. Journal of Taibah University Medical Sciences. 2017;12(3):241-248.

6. Porjadin G.V., Salmasi Gh.M., Kazimirskyy A.N. The immune system and inflammation. The modern prob-lems of allergology, immunology, immunophar-macology. 2002; 5:269-280.

7. Albandar J., Brunelle J., Kingman A. Destructive Periodontal Disease in Adults 30 Years of Age and Older in the United States, 1988-1994. Journal of Periodontology. 1999;70:13-29.

8. Brown L.J., Johns B.A., Wall T.P. The economics of periodontal diseases. Periodontology. 2000;29:223-234.

9. Loos B.G., Teeuw W.J., Nicu E.A. Plausible Mechanisms Explaining the Association of Periodontitis with Cardiovascular Diseases. In: Lynge Pedersen A. (eds) Oral Infections and General Health. Springer, Cham. 2016.

10. Mariano F.A., de Casia Orlandi Sandi J., Duque C., Hofling H.F. The role of immune system in the development of periodontal disease: a brief review. Rev Odonto Cienc. 2010;25(3):300-305.
11. Preshaw P.M. Detection and diagnosis of periodontal conditions amenable to prevention. BMC Oral Health. 2015; 15(1):S5. doi:10.1186/14726831-15-S1-S5.

12. Gomes F.I.F., Aragão M.G.B., Barbosa F.C.B. et al. Inflammatory Cytokines Interleukin-1 $\beta$ and Tumour Necrosis Factor- $a$ - Novel Biomarkers for the Detection of Periodontal Diseases: a Literature Review. Journal of Oral \& Maxillofacial Research. 2016;7(2):e2. doi:10.5037/jomr.2016.7202.

13. Preshaw P.M., Taylor J.J. How has research into cytokine interactions and their role in driving immune responses impacted our understanding of periodontitis? J Clin Periodontol. 2011;38(11):60-84.

14. Kasprzak A., Surdacka A., Tomczak M., Konkol M. Role of high endothelial postcapillary venules and selected adhesion molecules in periodontal diseases: a review. J Periodontal Res. 2013;48(1):1-21.

15. Bassiouny G. Expression of Platelet-Endothelial Cell Adhesion Molecule PECAM - 1 in Gingival Tissue of Patients with Chronic Periodontitis. J Am Scie. 2015;1(4):9-13.

\section{ORCID and contributionship:}

Nadiya O. Stasiuk: 0000-0003-0098-9421 A,B,C

Lev Yu. Plaviuk: 0000-0002-5117-8226 A,B,C,D,E

Sergiy V. Fedorov: 0000-0002-2202-4279 A,E,F

Vitaliy I. Gereliuk: 0000-0002-4193-6118 ${ }^{F}$

Nataliya P. Makhlynets: 0000-0002-1199-8086 ${ }^{D, F}$

Nila V. Neyko: 0000-0003-1931-1610 E, F

\section{Conflict of interest:}

The Authors declare no conflict of interest.

\section{CORRESPONDING AUTHOR Nadiya 0. Stasiuk \\ Ivano-Frankivsk National Medical University \\ 2 Grushevskogo str., 76000 Ivano-Frankivsk, Ukraine \\ tel: +380505875054 \\ email: stasiukn80@gmail.com}

Received: 07.06 .2020

Accepted: 16.12 .2020

A - Work concept and design, B - Data collection and analysis, C - Responsibility for statistical analysis, D-Writing the article, $\mathbf{E}$-Critical review, $\mathbf{F}$ - Final approval of the article 